\title{
Cell-based therapy for insulin-dependent diabetes mellitus
}

\author{
Shimon Efrat \\ Department of Molecular Pharmacology, Albert Einstein College of Medicine, 1300 Morris Park Avenue, Bronx, New York 10461, USA
}

\begin{abstract}
Insulin-secreting pancreatic $\beta$-cell lines represent a promising approach for treatment of insulindependent diabetes mellitus. Such cell lines can provide an abundant and reproducible source of $\beta$-cell material for transplantation. A number of highly differentiated $\beta$-cell lines have been developed using transgenic mice. These cells produce insulin amounts comparable to normal pancreatic islets and release it in response to physiological insulin secretagogues. Our laboratory has employed a reversible transformation approach to tightly regulate cell replication in these $\beta$-cell lines, both in culture and in vivo. Beta-cell lines can be modulated by gene transfer to improve their function and survival. We have utilized adenovirus genes, which downregulate antigen presentation and increase cell resistance to cytokines, to facilitate transplantation of mouse $\beta$ cells across allogeneic barriers. These approaches could be applied to the development of human $\beta$-cell lines by genetic engineering of isolated human islets.
\end{abstract}

European Journal of Endocrinology 138 129-133

\section{Introduction}

Insulin-dependent diabetes mellitus (IDDM) is an autoimmune disorder caused by a combination of poorly understood genetic and environmental factors. The disease results from a lymphocyte-mediated destruction of the insulin-producing $\beta$ cells in the pancreatic islets of Langerhans, which leads to insulin deficiency. IDDM is currently treated by insulin injections. However, it is difficult to provide in this way the accurate amounts of insulin needed at any given time, resulting in episodes of hyperglycemia or hypoglycemia. Hyperglycemia causes accumulated cell damage in many tissues, leading to the development of long-term complications in IDDM patients. The Diabetes Control and Complications Trial (1) has shown that tight regulation of blood glucose levels can effectively prevent these complications. Thus, IDDM patients will greatly benefit from an insulin delivery system which can continuously respond to the changing physiological needs of the organism by adjusting the amounts of insulin released into the circulation.

\section{Insulin gene therapy}

A number of groups have attempted to develop such a system through insulin gene therapy, by introducing into non- $\beta$ cells, such as pituitary cells or hepatocytes, the capacity to produce proinsulin and process it to mature insulin $(2,3)$. Autologous insulin-producing non- $\beta$ cells would avoid the immunological problems associated with recurring autoimmunity to $\beta$ cells, or with transplantation of allogeneic or xenogeneic $\beta$ cells. However, this approach requires complex gene transfer manipulations in the cells of each individual patient, either in vivo or in culture, raising the need to evaluate cell function and safety in each case. Perhaps the greatest difficulty in this approach has been to reconstruct in non- $\beta$ cells the ability to regulate insulin secretion, which is characteristic of normal $\beta$ cells. The islet $\beta$ cells are uniquely equipped not only with the ability to produce insulin, but also with sensing and coupling mechanisms to regulate its release in response to changes in the blood concentration of a variety of molecules, most notably glucose (4). Thus the optimal treatment of IDDM is likely to be the preservation or replacement of the $\beta$-cell mass.

\section{Advantages of $\beta$-cell lines}

In principle, the $\beta$-cell mass can be maintained by preventing or decreasing the autoimmune destruction of $\beta$ cells, by induction of islet regeneration, by $\beta$-cell replacement through transplantation, or most likely by a combination of all these approaches. In spite of increasing understanding of autoimmunity and of $\beta$-cell development, transplantation remains the most feasible approach in the near future for restoration of normal $\beta$-cell function in IDDM patients. To develop a $\beta$-cell transplantation therapy for diabetes on a large scale, two major obstacles must be overcome: availability of an abundant source of $\beta$ cells, and prevention of transplant 
destruction in the autoimmune environment. I will review here work from our laboratory, as well as from other groups, that has focused on these two goals.

The problem of adequate cell supply is unlikely to be solved by isolated islets. The supply of human islets is limited by the number of donors. Isolation of large numbers of animal islets is laborious, costly, and difficult to perform in a reproducible manner. The limitations on $\beta$-cell transplantation due to cell supply would be eliminated by the development of universal human or animal $\beta$-cell lines. Such cell lines would provide an abundant source of $\beta$-cell material for transplantation, with well-defined and reproducible properties. The cells could be selected in culture for optimal function and could be further modulated by gene transfer to improve their function and survival. They could also be extensively screened for known pathogens to assure transplant safety.

\section{Allogeneic versus xenogeneic $\beta$-cell sources}

Normal adult $\beta$ cells are difficult to propagate in culture. The $\beta$-cell lines developed to date have relied on oncogenic transformation to stimulate cell growth. This approach has worked well with rodent $\beta$ cells (512). Transformed human $\beta$-cell lines have proved much harder to generate, since cell transformation often leads to dedifferentiation (13). However, a highly differentiated human $\beta$-cell line remains the ultimate goal for cell therapy of IDDM, as opposed to xenogeneic $\beta$-cell lines, for several reasons. Allografts are much easier to protect from immune rejection, compared with xenografts. Hyperacute rejection of xenografts is caused by recognition of cell surface carbohydrate antigens by naturally occurring antibodies (14). Recent work involving genetic engineering of tissues to inhibit complement fixation has shown some promise in extending xenograft survival (15). Nevertheless, xenotransplantation remains a formidable challenge. Another advantage of human $\beta$ cells is that they are likely to be more compatible with the human physiological environment compared with most animal $\beta$ cells. In addition, human insulin is likely to be more effective in humans than most animal insulins. Xenografts have raised numerous safety concerns, chief among which is the introduction of unknown animal pathogens into the human population. Another concern is that immunogenic peptides shed by xenografts may elicit immune responses, which could result in cross-reactivity against host proteins, thus potentially triggering new autoimmune responses.

The approach in our laboratory has been to develop the genetic strategies for $\beta$-cell manipulation in animal (mouse) models, with the hope that they can be applied to the engineering of human islet $\beta$ cells. However, if functional human $\beta$-cell lines continue to be hard to generate, these approaches could be targeted towards engineering of an animal $\beta$-cell line suitable for human transplantation, such as from a porcine origin. Although less than optimal for human transplantation for the reasons mentioned above, animal $\beta$ cells may turn out to have certain advantages. For example, they could be better protected from recurring autoimmunity directed against human $\beta$ cells. In addition, xenogeneic cells transplanted in immunoisolation devices (see below) should be more readily destroyed by the immune system in case of cell escape from a failing device. Xenogeneic $\beta$ cells can be engineered to produce human insulin (16), although non-human insulins, such as porcine, have been successfully used in humans. In addition, IDDM patients often develop antibodies to human insulin, therefore a non-human insulin should not necessarily be more immunogenic.

\section{Transformed rodent $\beta$-cell lines}

A number of transformed rodent $\beta$-cell lines have been generated and extensively studied (5-12). Although many of them deviate considerably from normal $\beta$ cells in the regulation of insulin production and secretion, a few of these cell lines have manifested a remarkably well-differentiated phenotype $(9,11,12,17-19)$, in particular the biosynthesis of insulin amounts, and responses to insulin secretagogues, which are similar to those of normal $\beta$ cells. In evaluating the potential of employing transformed $\beta$ cells for cell therapy of IDDM, two major issues have to be addressed.

\section{Cell function}

Transformed $\beta$ cells should produce sufficient amounts of insulin and secrete it in a regulated manner in response to physiological concentrations of insulin secretagogues. These cells should be able to maintain functional stability for long periods in culture and in vivo.

\section{Safety}

Cell proliferation should be tightly regulated. This is needed not only to prevent uncontrolled cell expansion, but is also likely to contribute to improved cell function, since mature $\beta$ cells do not proliferate under normal conditions.

We have established a number of transgenic mouse $\beta$-cell lines using SV40 T antigen (Tag) as the transforming oncoprotein. Expression of Tag under control of the insulin promoter in transgenic mice leads to the formation of $\beta$-cell tumors (20), which can be cultured to derive continuous cell lines $(7,9,10,12)$. We termed these cells $\beta$-tumor cells $(\beta \mathrm{TC})$. Functional analyses of these cell lines has demonstrated that transformed $\beta$ cells can maintain a high level of differentiation with respect to insulin biosynthesis and regulated secretion. $\beta \mathrm{TC}$ cells produce about a third of the normal amounts of insulin found in non-transformed $\beta$ cells, and respond 
to all physiological stimuli of insulin secretion $(7,8$, 17-19). However, when transplanted into syngeneic hosts these cells proliferate in an unregulated manner, which eventually can cause hypoglycemia.

\section{Reversible transformation of $\beta$ cells}

In an attempt to regulate $\beta$ TC replication we placed the Tag oncogene under a conditional gene expression system (19). We utilized the bacterial tetracycline (Tc) operon regulatory system to control the expression of Tag. The tetracycline repressor (tetR) binds specifically to a palindromic operator sequence (tet-op). The binding is inhibited when the repressor is attached to the Tc ligand. By fusing the tetR with the transcription activating domain of the herpes simplex virus VP16 protein, Gossen and Bujard have changed the repressor into a potent Tc-controlled transactivator (tTA), which turns on genes flanked by the specific tet-op sites (21). We generated transgenic mice with the tTA gene under control of the insulin gene regulatory region (RIP-tTA), which constitutively produce tTA in $\beta$ cells (19). In a separate lineage of transgenic mice, the Tag gene was introduced under control of a minimal promoter combined with tet-op sequences (tet-Tag). Both transgenic lines appeared phenotypically normal. When the two lines were crossed to each other, the doubletransgenic mice developed $\beta$-cell tumors. This resulted from a $\beta$-cell-specific activation of Tag expression by tTA. The tumors were cultured to derive a stable cell line, denoted $\beta$ TC-tet. These cells underwent complete growth arrest in the presence of Tc, both in culture and in vivo, as demonstrated by incorporation of $\left[{ }^{3} \mathrm{H}\right]$ thymidine or BrdU into replicating DNA.

Cultured $\beta$ TC-tet cells manifest correct responsiveness to glucose in the physiological concentration range. Preliminary studies indicate that growth arrest results in further improvement of cell function. Most notably, a several-fold increase in insulin content, up to the levels found in normal $\beta$ cells, is consistently observed (M Surana, N Fleischer \& S Efrat, unpublished results). To evaluate their capacity to maintain euglycemia in vivo, $\beta$ TC-tet cells were implanted intraperitoneally into streptozotocin-diabetic syngeneic hosts. The cell implantation led to correction of hyperglycemia (19), demonstrating the ability of $\beta$ TC-tet cells to function as normal $\beta$ cells in vivo. As observed in the past with other $\beta \mathrm{TC}$ lines, the implanted cells continued to proliferate in mice not treated with Tc, which resulted in hypoglycemia and premature death. In contrast, in mice implanted with slow-release Tc pellets blood glucose levels were stabilized in the normal range for the observation period of four months. These findings indicate that the cells undergo growth arrest following Tc-induced inhibition of Tag expression, but maintain viability and are capable of normal glucose sensing and insulin production and secretion. The Tc treatment was completely reversible: when the Tc pellets were removed from the mice at the end of the four-month period of treatment, cell proliferation resumed, resulting in the development of hypoglycemia and tumors within one month. This finding indicates that the $\beta$ TC-tet cells maintain a proliferative capacity during a prolonged period of growth arrest, which allows renewed cell replication once Tag expression is restored.

This regulatory system works well because of the strict dependence of the transformed $\beta$ cells on continuous expression of the Tag oncoprotein for their proliferation. The development of $\beta$-cell tumors in the transgenic mice is a relatively rare event, occurring only in a small fraction of the islets (20). This has suggested that tumor development requires additional genetic changes in the cells. However, the findings with the $\beta \mathrm{TC}$-tet cells suggest that these additional events do not involve genes that regulate the cell cycle, since the cells continue to require the activities of Tag to remain in cycle.

The Tc regulatory system would be rendered more useful in employing conditionally transformed cells in transplantation if the oncogene could be shut off in the absence of the Tc ligand. A mutant tetR developed recently by Bujard, which requires Tc for DNA binding and remains inactive in the absence of Tc (22), may allow this. This reverse system will permit the induction of cell growth in culture in the presence of Tc, and cause growth arrest by removing Tc upon transplantation in vivo.

\section{Protection of transplanted cells from immune rejection}

Much progress has been made in recent years in developing new ways to prevent allograft rejection. These approaches are intended to replace prolonged immunosuppression, which compromises host immune defences against infections and neoplasia. Cell encapsulation in polymer membranes has reached the stage of clinical trials in patients with neural disorders (23). Intrathymic transplantation of islets and bone marrow has shown promise in induction of donor-specific tolerance $(24,25)$. In addition, a variety of immune effector molecules have been employed in attempts to manipulate donor cells genetically to resist immune attacks $(26,27)$.

\section{The use of adenovirus genes to prolong the survival of transplanted $\beta$ cells}

In collaboration with Dr Marshall Horwitz we have utilized viral genes to modulate the immunogenicity of $\beta$ cells, to prolong their survival in allografts. A number of viruses have evolved proteins which are capable of downregulating the host immune response against virusinfected cells. These can be used to render mammalian cells resistant to certain immune responses. One example 
is human adenoviruses (Ad), which encode a number of such proteins in the early region 3 (E3). One of these is a $19 \mathrm{kDa}$ glycoprotein (gp19), which binds to the heavy chain of selected class I major histocompatibility complex (MHC) haplotypes and prevents its transport out of the endoplasmic reticulum (28). Significant evidence suggests that cell surface class I MHC-mediated antigen presentation plays a major role in allograft rejection. Islets from mice deficient in $\beta_{2}$-microglobulin, which lack cell surface class I MHC molecules (29, 30), manifest a markedly increased survival, compared with normal islets, when transplanted under the renal capsule of allogeneic mice $(31,32)$. Anti-class I MHC F(ab) 2 antibodies were shown to prolong allograft survival, as well as survival of human islet xenografts in mice (33). These results suggest that genetic manipulation of class I MHC antigen presentation may facilitate transplantation of allogeneic $\beta$ cells.

In addition to gp19, three other proteins encoded in the Ad2 E3 region have immunoregulatory activities. A protein of $14.7 \mathrm{kDa}$, as well as a heterodimer of the $10.4 \mathrm{kDa}$ and $14.5 \mathrm{kDa}$ proteins, can inhibit tumor necrosis factor- $\alpha$-induced cytolysis of Ad-infected cells $(28,34)$. All of the E3 polypeptides are produced from transcripts generated from a common viral promoter by alternative splicing.

To evaluate the potential use of these immunoregulatory viral proteins in allogeneic cell transplantation, we expressed the Ad E3 genes in pancreatic $\beta$ cells in transgenic mice under control of the insulin promoter (RIP-E3), and transplanted transgenic islets under the renal capsule of allogeneic recipients (35). Donor islets from RIP-E3 (C57BL/6×BALB/c/F1 (haplotype H-2 ${ }^{\mathrm{b} / \mathrm{d}}$ )) transgenic animals were transplanted into either BALB/c or $\mathrm{C} 57 \mathrm{BL} / 6$ parental strain recipients. The islets survived in the BALB/c mice for over three months, which was the last time point examined. In contrast, non-transgenic $\mathrm{C} 57 \mathrm{BL} / 6 \times \mathrm{BALB} / \mathrm{c} / \mathrm{F} 1$ islets were all rejected by BALB/c recipients around three weeks following transplantation. Histological analysis of the surviving RIP-E3 islets showed no inflammatory response within the islets. In contrast to the transgenic donor islets that were accepted by $\mathrm{BALB} / \mathrm{c}$ mice, islets from the same donors were rejected by $\mathrm{C} 57 \mathrm{BL} / 6$ animals. The RIP-E3 mice were also bred into the BALB/k background $\left(\mathrm{H}-2^{\mathrm{k}}\right)$, and islets from these mice were transplanted into $\mathrm{BALB} / \mathrm{c}$ mice. In this case, too, transplant survival was demonstrated at three months, compared with three weeks in non-transgenic controls (S Efrat \& M S Horwitz, unpublished results). Experiments with cultured cells transfected with the Ad gp19 gene have shown that the gp19 protein binds class I MHC heavy chains of different haplotypes with different affinities $(36,37)$, which may explain the variations in protection observed among RIP-E3 islets from different haplotypes. Taken together with recent findings that demonstrate the ability of the Ad E3 genes to prevent autoimmune destruction of $\beta$ cells in a mouse model of virus-induced IDDM (38), and to prolong gene expression in an animal model of gene therapy utilizing Ad vectors
(39), our results suggest that the Ad E3 genes may be useful in engineering $\beta$-cell lines to reduce their immunogenicity and extend their survival in allogeneic transplantation.

\section{Future prospects}

The work in recent years has demonstrated that transformed $\beta$-cell lines can maintain the main differentiated functions of normal $\beta$ cells, namely insulin biosynthesis and regulated secretion. The development of approaches to tightly regulate cell replication made it possible to use these cells in restoring and maintaining euglycemia in diabetic animals. Cell engineering with adenovirus genes that reduce cell immunogenicity allowed successful transplantation across allogeneic barriers without immunosuppression or immunoisolation. These genetic manipulations can be applied in the future to cultured human islets, to derive a universal donor human $\beta$-cell line. Despite remaining challenges, genetically engineered $\beta$ cells hold the promise of replacing insulin injections as an accurate, convenient and safe way for long-term maintenance of euglycemia in IDDM patients.

\section{Acknowledgements}

The research in my laboratory has been supported by the Juvenile Diabetes Foundation International, by the NIDDK Shannon Award, and by a Career Scientist Award from the Irma T Hirschl Foundation. I am indebted to all my co-workers who have contributed to the publications cited in this review.

\section{References}

1 The Diabetes Control and Complications Trial Research Group. The effect of intensive treatment of diabetes on the development and progression of long-term complications in insulin-dependent diabetes mellitus. New England Journal of Medicine $1993329977-$ 986.

2 Kolodka TM, Finegold M, Moss L \& Woo SL. Gene therapy for diabetes mellitus in rats by hepatic expression of insulin. Proceedings of the National Academy of Sciences of the USA 1995 92 3293-3297.

3 Lipes MA, Cooper EM, Skelly R, Rhodes CJ, Boschetti E, Weir GC et al. Insulin-secreting non-islet cells are resistant to autoimmune destruction. Proceedings of the National Academy of Sciences of the USA 199693 8595-8600.

4 Holz GG \& Habener JF. Signal transduction crosstalk in the endocrine system: pancreatic $\beta$ cells and the glucose competence concept. Trends in Biochemical Sciences 199217 388-393.

5 Chick WL, Warren S, Chute RN, Like AA, Lauris V \& Kitchen KC. A transplantable insulinoma in the rat. Proceedings of the National Academy of Sciences of the USA 197774 628-630.

6 Santerre RF, Cook RA, Crisel RMD, Sharp JD, Schidt RJ, Williams DC et al. Insulin synthesis in a clonal cell line of simian virus 40-transformed hamster pancreatic beta cells. Proceedings of the National Academy of Sciences of the USA 198178 43394342.

7 Efrat S, Linde S, Kofod H, Spector D, Delannoy M, Grant S et al. Beta-cell lines derived from transgenic mice expressing a hybrid 
insulin gene-oncogene. Proceedings of the National Academy of Sciences of the USA $1988859037-9041$.

8 D'Ambra R, Surana M, Efrat S, Starr RG \& Fleischer N. Regulation of insulin secretion from B-cell lines derived from transgenic mice insulinomas resembles that of normal B-cells. Endocrinology 1990 $1262815-2822$

9 Miyazaki J-I, Araki K, Yamato E, Ikegami H, Asano T, Shibasaki Y et al. Establishment of a pancreatic $\beta$ cell line that retains glucoseinducible insulin secretion: special reference to expression of glucose transporter isoforms. Endocrinology 1990127 126-132.

10 Hamaguchi K, Gaskins HR \& Leiter EH. NIT-1, a pancreatic $\beta$-cell line established from a transgenic NOD/Lt mouse. Diabetes 1991 $40842-849$.

11 Asfari M, Janjic D, Meda P, Li G, Halban PA \& Wollheim CB. Establishment of 2-mercaptoethanol-dependent differentiated insulin-secreting cell lines. Endocrinology 1992130 167-178.

12 Radvanyi F, Christgau S, Baekkeskov S, Jolicoeur C \& Hanahan D. Pancreatic $\beta$ cells cultured from individual preneoplastic foci in a multistage tumorigenesis pathway: a potentially general technique for isolating physiologically representative cell lines. Molecular and Cellular Biology 199313 4223-4232.

13 Wang S, Beattie GM, Mally MI, Cirulli V, Itkin-Ansari P, Lopez AD et al. Isolation and characterization of a cell line from the epithelial cells of the human fetal pancreas. Cell Transplantation $1997659-67$

14 Cooper DK, Koren E \& Oriol R. Oligosaccharides and discordant xenotransplantation. Immunology Review 1994141 31-58.

15 Schmoeckel M, Nollert G, Shahmohammadi M, Young VK, Chavez G, Kasper-Konig W et al. Prevention of hyperacute rejection by human decay accelerating factor in xenogeneic perfused working hearts. Transplantation $199662729-734$.

16 Clark SA, Ouaade C, Constandy H, Hansen P, Halban P, Ferber S et al. Novel insulinoma cell lines produced by iterative engineering of GLUT2, glucokinase, and human insulin expression. Diabetes $199746958-967$.

17 Efrat S, Leiser M, Surana M, Tal M, Fusco-DeMane D \& Fleischer N. Murine insulinoma cell line with normal glucose-regulated insulin secretion. Diabetes 199342 901-907.

18 Knaack D, Fiore DM, Surana M, Leiser M, Laurance ME, FuscoDeMane D et al. Clonal insulinoma cell line which stably maintains correct glucose responsiveness. Diabetes 199443 1413-1417.

19 Efrat S, Fusco-DeMane D, Lemberg H, Emran OA \& Wang S. Conditional transformation of a pancreatic $\beta$-cell line derived from transgenic mice expressing a tetracycline-regulated oncogene. Proceedings of the National Academy of Sciences of the USA $1995923576-3580$.

20 Hanahan D. Heritable formation of pancreatic B-cell tumours in transgenic mice expressing recombinant insulin simian virus 40 oncogenes. Nature $1985315115-122$.

21 Gossen M \& Bujard H. Tight control of gene expression in mammalian cells by tetracycline-responsive promoters. Proceedings of the National Academy of Sciences of the USA 199289 5547-5551.

22 Gossen M, Freundlieb S, Bender G, Muller G, Hillen W \& Bujard H. Transcriptional activation by tetracyclines in mammalian cells. Science 1995268 1766-1769.

23 Aebischer P, Schluep M, Deglon N, Joseph J-M, Hirt L, Heyd B et al. Intrathecal delivery of CNTF using encapsulated genetically modified xenogeneic cells in amyotrophic lateral sclerosis patients. Nature Medicine 19962 696-699.
24 Posselt AM, Barker CF, Tomaszewski JE, Markmann JF, Choti MA \& Naji A. Induction of donor-specific unresponsiveness by intrathymic islet transplantation. Science 1990249 1293-1295.

25 Posselt AM, Odorico JS, Barker CF \& Naji A. Promotion of pancreatic islet allograft survival by intrathymic transplantation of bone marrow. Diabetes $199241771-775$.

26 Lau HT, Yu M, Fontana A \& Stoeckert CJ. Prevention of islet allograft rejection with engineered myoblasts expressing FasL in mice. Science 1996273 109-112.

27 Pearson TC, Alexander DZ, Hendrix R, Elwood ET, Linsley PS, Winn KJ et al. CTLA4-Ig plus bone marrow induces long-term allograft survival and donor-specific unresponsiveness in the murine model. Evidence for hematopoietic chimerism. Transplantation 199661 997-1004.

28 Wold WSM \& Gooding LR. Region E3 of adenovirus: a cassette of genes involved in host immunosurveillance and virus-cell interactions. Virology $19911841-8$.

29 Zijstra M, Li E, Sajjadi F, Subramani S \& Jaenisch R. Germ-line transmission of a disrupted $\beta_{2}$-microglobulin gene produced by homologous recombination in embryonic stem cells. Nature 1989 342 435-438.

30 Koller BH \& Smithies O. Inactivating the $\beta_{2}$-microglobulin locus in mouse embryonic stem cells by homologous recombination. Proceedings of the National Academy of Sciences of the USA 198986 8932-8935.

31 Markmann JF, Bassiri H, Desai NM, Odorico JS, Kim JI, Koller BH et al. Indefinite survival of MHC class I-deficient murine pancreatic islet allografts. Transplantation 199254 1085-1089.

32 Osorio RW, Ascher NL, Jaenisch R, Freise CE, Roberts JP \& Stock PG. Major histocompatibility complex class I deficiency prolongs islet allograft survival. Diabetes 199342 1520-1527.

33 Faustman D \& Coe C. Prevention of xenograft rejection by masking donor HLA class I antigens. Science 1991252 1700-1702.

34 Wold WSM. Adenovirus genes that modulate the sensitivity of virus-infected cells to lysis by TNF. Journal of Cell Biochemistry 199353 329-335.

35 Efrat S, Fejer G, Brownlee M \& Horwitz MS. Prolonged survival of murine pancreatic islet allografts mediated by adenovirus early region 3 immunoregulatory transgenes. Proceedings of the National Academy of Sciences of the USA 199592 6947-6951.

36 Cox JH, Yewdell JW, Eisenlohr LC, Johnson PR \& Bennink JR. Antigen presentation requires transport of MHC class I molecules from the endoplasmic reticulum. Science 1990247 715-718.

37 Beier DC, Cox JH, Vining DR, Cresswell P \& Engelhard VH. Association of human class I MHC alleles with the adenovirus E3/19K protein. Journal of Immunology $19941523862-3872$.

38 von Herrath MG, Efrat S, Oldstone MBA \& Horwitz MS. Expression of adenoviral E3 transgenes in $\beta$ cells prevents autoimmune diabetes. Proceedings of the National Academy of Sciences of the USA $1997949808-9813$.

39 Ilan Y, Droguett G, Roy Chowdhury N, Li Y, Sengupta K, Thummala NR et al. Insertion of the adenoviral E3 region into a recombinant viral vector prevents antiviral humoral and cellular immune responses and permits long-term gene expression. Proceedings of the National Academy of Sciences of the USA 1997 $942587-2592$.

Received 29 August 1997

Accepted 1 September 1997 